\title{
Коллективное использование производственных мощностей в условиях цифровой экономики
}

\author{
И. Рахмилевич ${ }^{1}$, О. Хомутская, к. т.н. ${ }^{2}$, С. Ванцов, к. т. н. ${ }^{3}$
}

УДК 004.9::338.32 | ВАК 05.13.10

\begin{abstract}
Экономика совместного потребления является частью четвертой промышленной революции [1]. Базовый принцип совместного потребления коллективное использование ресурса, временный доступ к нему, который оказывается выгоднее, чем владение этим ресурсом. Сегодня на такой основе построено множество бизнесов в сфере услуг, однако существует серьезный потенциал применения этой модели и в производстве материального продукта. В статье рассмотрены возможности совместного использования производственных мощностей, находящихся во владении мастерских, лабораторий и отдельных людей, путем создания шеринговой платформы для оказания услуг по производству товаров и аренде оборудования. Платформа позволяет сократить издержки производства и получить доступ к компетенциям опытных конструкторов и технологов.
\end{abstract}

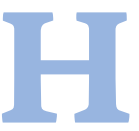

а сегодняшний день компании, в основе которых лежит экономическая модель совместного потребления (шеринговая экономика, англ. sharing economy), занимают лидирующие позиции [2]. Такие бренды, как Uber, Alibaba, Facebook и Airbnb, предоставляют сервис или платформу, где спрос встречается с предложением. Платформы создают основу для доверия, выступая гарантами при проведении денежных операций, защищая от мошенников и ранжируя участников. Пользователями платформ являются обычные люди, благодаря чему появляется возможность задействовать малые активы в виде свободного пассажирского места в автомобиле в случае Uber или незанятой комнаты в доме в случае Airbnb. Стоимость услуги или товара на платформе ниже, чем при обращении за тем же товаром или услугой к компаниям из смежной области - такси в случаe Uber и гостиницы в случае Airbnb. Спрос и предложение встречаются напрямую, без посредника, а большое количество схожих товаров или услуг на платформе создает конкурентную среду, повышая их качество.

Сервисов, предоставляющих в коллективное потребление нематериальные услуги, достаточно много, и логичный шаг вперед - это переход к созданию материальных объектов на тех же принципах шеринговой экономики. В производственной сфере это означает совместное использование оборудования (equipment sharing) и сырья

МАИ (НИУ), магистрант, damougod@gmail.com

МАИ (НИУ), доцент, khomutskayaov@gmail.com.

МАИ (НИУ), доцент, МАИ, vancov@medpractika.ru. (resource sharing) для создания товаров по требованию, то есть на заказ, и сдачи оборудования в аренду.

Основная цель предлагаемой платформы - задействование малых активов, которыми владеют отдельные люди и лаборатории. Коэффициент использования такихактивов, как правило, крайне низок, результатом чего становятся увеличенный срок окупаемости и низкая прибыль от владения ими.

Как видно из диаграммы (рис. 1), 55\% оборудования используется реже одного раза в неделю: множество высокоточного оборудования простаивает в лабораторияхпри университетах и центрах молодежного инновационного творчества (ЦМИТ), где 3D-принтеры, лазерные резчики и фрезерные станки включаются порой два раза в месяц. Для таких исполнителей работа на заказ и предоставление оборудования в пользование сторонним лицам и организациям - одна из основных статей дохода. Однако зачастую потенциальный заказчик не знает о существовании ЦМИТов и о том, какие услуги предоставляют подобные лаборатории. Создание платформы направлено на
9\% Каждый день
36\% 2-3 раза в неделю
55\% Раз в неделю и реже

Рис. 1. Частота использования оборудования на примере центра молодежного инновационного творчества 
решение проблемы задействования малых активов и загрузки малоиспользуемого оборудования.

В отличие от других существующих платформ, особенностью новой будет объединение доступа к большому числу владельцев разнообразного оборудования и агрегирование информации с узконаправленных платформ. Реализация такого подхода сделает возможным произвести новый продукт на одной платформе, поручив всё производство одному исполнителю, а не искать соисполнителей и компоненты на разных платформах. Продуктом может быть что угодно: не выпускающиеся больше запасные части, новые предметы интерьера и декора, корпуса для разрабатываемых устройств, 3D-модели -всё, что не требует индустриальных масштабов производства и проведения обширного цикла испытаний. Более того, можно будет предоставить в пользование на небольшой срок оборудование и, при необходимости, сырье: лазерный резчик для гравировки, паяльную станцию с соответствующими расходными материалами, столярную мастерскую для создания чего-либо своими руками и т.д.

Платформа представляет собой сервис в виде сайта и приложения для смартфонов. Пользователями платформы являются исполнители и заказчики. Исполнители - это отдельные люди, владеющие оборудованием и (или) профессиональными навыками, лаборатории, мастерские, центры молодежного инновационного творчества и другие подобные организации. Заказчиками являются люди, желающие заказать производство продукта и (или) арендовать станок. Далее по тексту под пользователями будут пониматься именно заказчики.

Рассмотрим процесс заказа нового продукта в обычном варианте, без использования предлагаемой платформы (рис. 2). Человек, выступающий заказчиком и желающий получить некий уникальный товар, осуществляет поиск в Интернете исполнителей, работающих на заказ. Анализирует результаты поиска, выбирает подходящие сайты-исполнители. Затем ему предстоит поочередно разобраться с несколькими системами регистрации и оформления заказа на выбранных сайтах, причем в худшем случае на них может и не быть системы онлайнзаказов, и тогда заказчику придется связаться с исполнителем по электронной почте или по телефону, чтобы договориться об оформлении заказа в личной беседе. Весь этот процесс растягивается во времени на несколько дней, и заказчик, столкнувшись с трудностями, может совсем отказаться от своей идеи. С другой стороны, исполнители, не представленные в Интернете, и исполнители, представленные там, но не имеющие систем онлайнзаказов, оказываются в неравных условиях по сравнению со своими более продвинутыми конкурентами и теряют потенциальных клиентов.

Важнейшей отличительной функцией новой платформы является автоматический поиск исполнителей. Используя предоставленные фильтры, заказчик может сузить круг исполнителей до подходящих ему и выбрать, кому сделать заказ. Отбор может быть осуществлен по территориальному признаку, чтобы заказчик мог минимизировать затраты на курьерские службы доставки либо совсем не тратиться на них; имеются также опции выбора по отзывам и рейтингу.

Организация диалога пользователя с платформой показана на рис. 3. В первую очередь платформа запросит адрес пользователя или его местоположение в более общем виде - это необходимо для отбора ближайших потенциальных исполнителей. Далее последует уточнение: идет ли речь о заказе на изготовление товара или об аренде станка; для заказа используется один набор фильтров, для аренды - другой. Затем пользователю предоставляются фильтры для подбора подходящей мастерской.

Конечно, фильтры не обязательны для заполнения, и заказчик может просто выбрать ближайшего исполнителя, охватывающего большой спектр работ, и связаться с ним или отправиться к нему. Однако для реализации всех возможностей платформы по автоматическому подбору исполнителей, способных удовлетворить пожелания пользователя, следует воспользоваться предлагаемыми

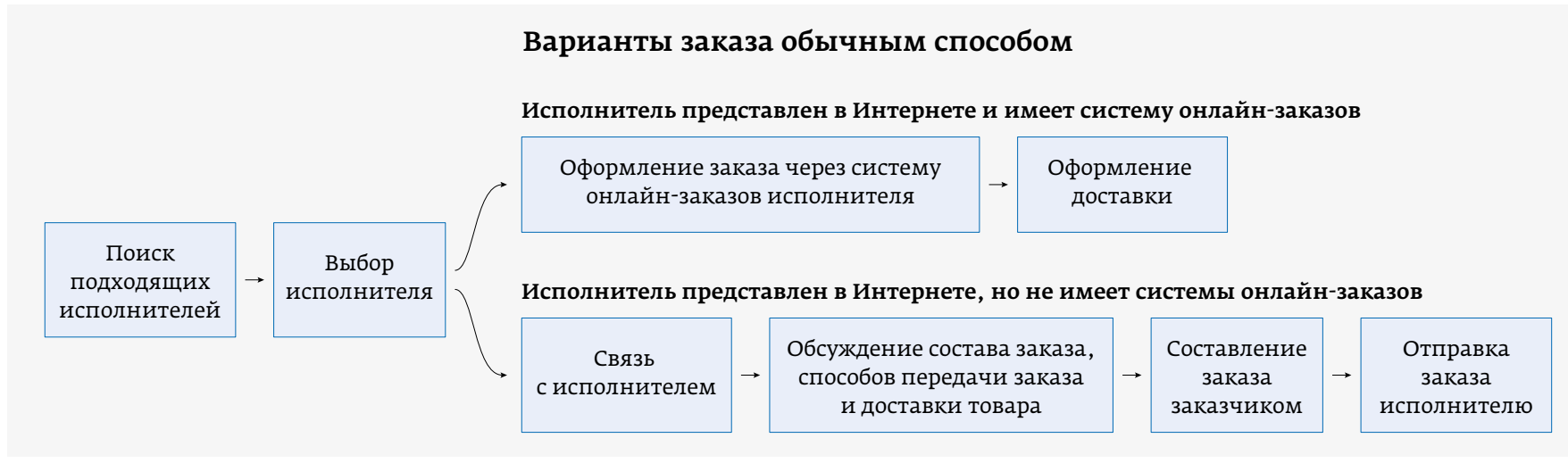

Рис. 2. Заказ товара обычным способом 


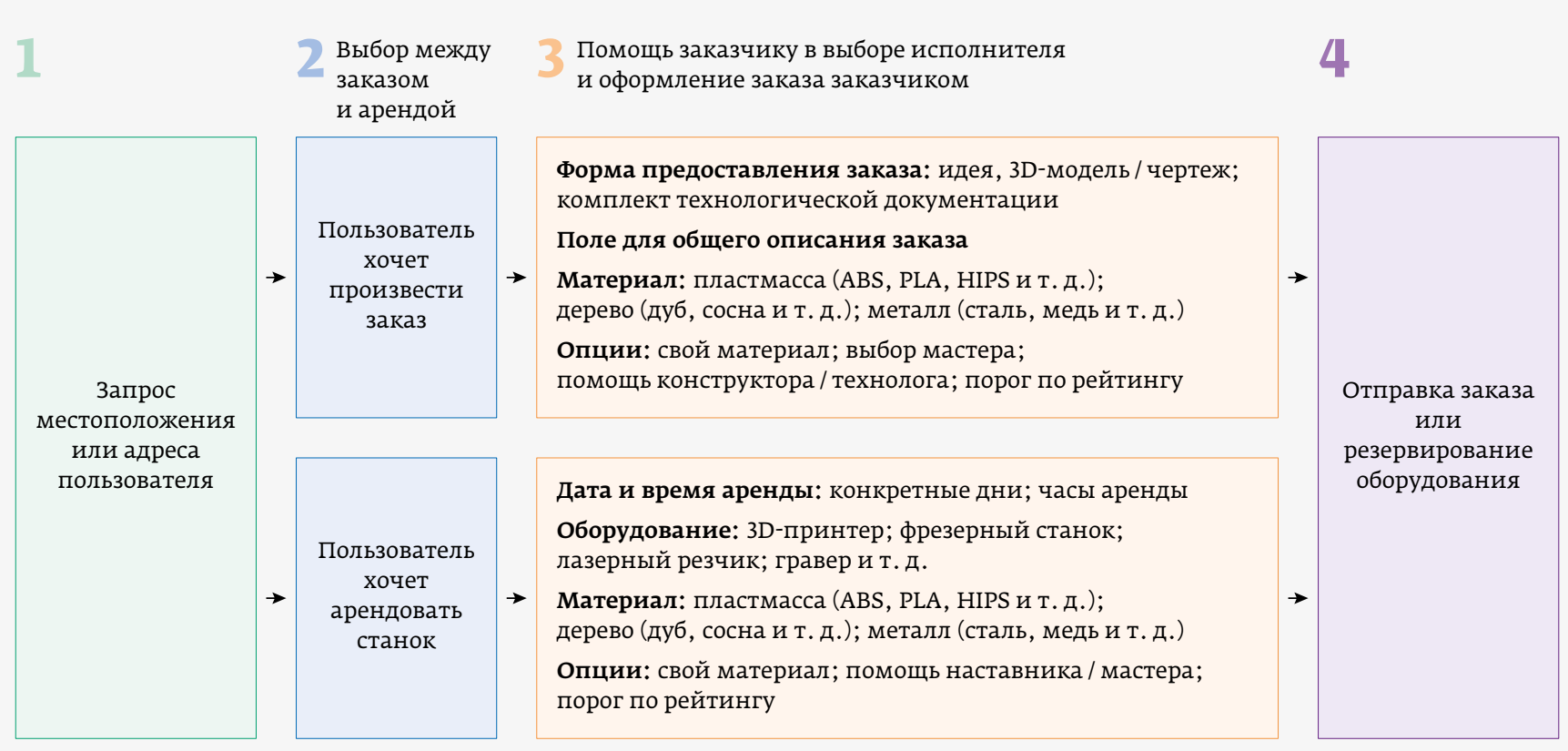

Рис. 3. Взаимодействие платформы с пользователем в процессе оформления заказа и выбора исполнителя

ею фильтрами, которые служат критериями поиска исполнителей и определяют ряд существенных характеристик изделия. Для общего описания заказа используются текстовые поля, заполняемые пользователем в свободной форме.

Пользователи могут представлять свои заказы в самой различной форме, начиная от образа (картинки), по которому должен быть воссоздан объект, и заканчивая исполнительными программами для станков с ЧПУ, готовыми 3D-моделями и Gcode-файлами для 3D-принтера. Для того чтобы помочь сориентироваться в этом вопросе, сервис может предоставить информацию о соответствующих возможностях исполнителя.

Качество конечного продукта во многом зависит от человека, то есть выполняющего заказ мастера, поэтому заказчики также могут выбирать мастеров, если исполнитель предоставляет такую возможность. В свою очередь, мастера могут вести свои аккаунты на платформе с целью накопления портфолио и легкого переноса своих данных в случае смены места работы.

Указав в фильтрах необходимые параметры, заказчик получает автоматически собранный список подходящих исполнителей. Оценив возможности потенциальных контрагентов из этого списка, отзывы и другую информацию о них, предоставленную сервисом, он выбирает понравившегося исполнителя и может сразу оставлять заказ на платформе.

Предлагаемая платформа полезна не только заказчикам товаров и арендаторам оборудования, облегчая и ускоряя нахождение подходящего и близко расположенного исполнителя. Она также уравнивает возможности исполнителей в части доступа к широкому кругу заказчиков, собрав их в одном приложении или сервисе. Заказы будут храниться сервисом в электронном виде, что удобно обеим взаимодействующим сторонам.

Для эффективной работы сервису необходимо заранее получить все данные об исполнителях. От них потребуется контактная информация, информация о режиме работы, используемых материалах и оборудовании, типах выполняемых работ, возможности использовать сторонние материалы, готовности предоставить оборудование в аренду, характеристики оборудования (точность, размер рабочей зоны и др.) и т.д. Полезно будет также по возможности предоставить фото и видео с демонстрацией примеров работы. Вариант формы для ввода всей информации приведен на рис. 4. В процессе работы с платформой исполнители будут ранжироваться по отзывам. Учитываться будет удовлетворенность клиента и личностные качества исполнителя, например, заинтересованность в работе с заказом, пунктуальность, отношениекклиенту ит.п.

Средства на свою поддержку платформа получит с подписки. Исполнители - лаборатории, мастерские и отдельные люди - должны будут платить за присутствие на платформе, чтобы они были представлены в поиске и информация о них обновлялась. Размер платы за подписку будет зависеть от величины парка оборудования, количества мастеров и заказов - это необходимо для того, чтобы цена доступа к платформе не превышала порога, приемлемого для самых мелких исполнителей, вплоть 


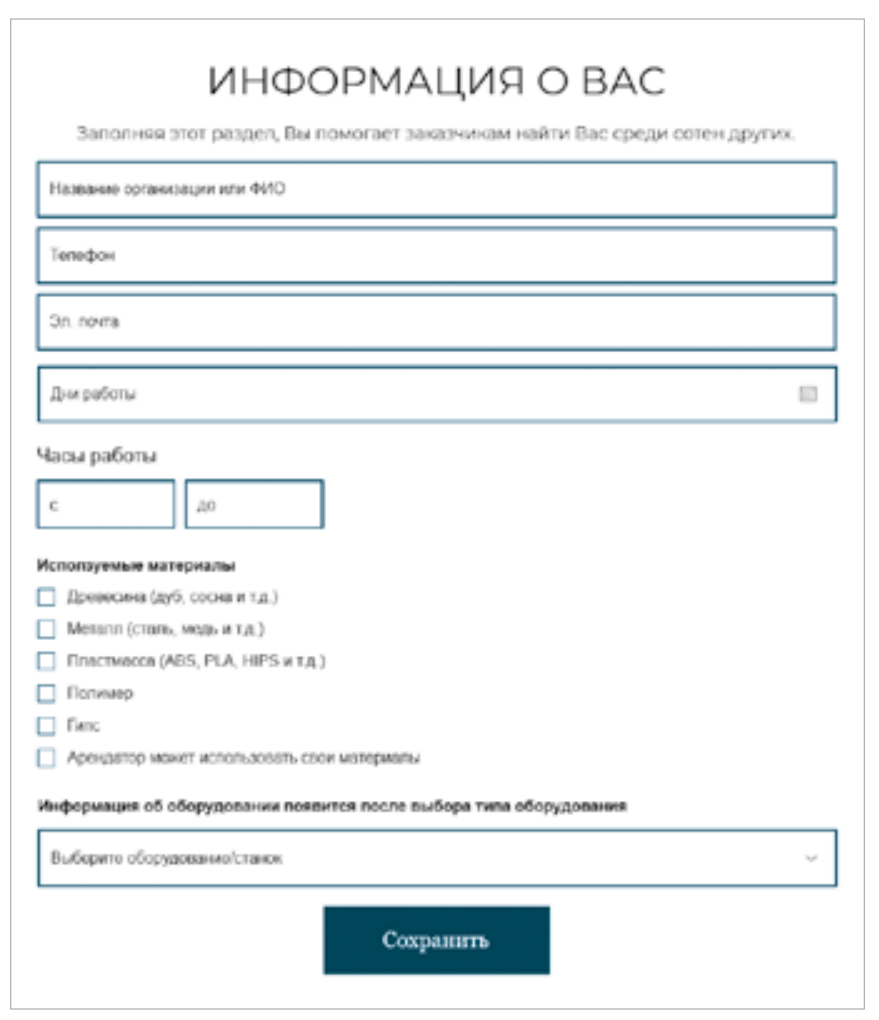

Рис. 4. Пример формы, заполняемой исполнителем

до отдельных мастеров. Для привлечения исполнителей платформа некоторое время после начала работы будет бесплатна.

Для определения заинтересованности исполнителей в типе работ (под типом работ в данном случае понимается состав выполняемых этапов создания изделия) произведен анализ данных нескольких платформ, специализирующихся на 3D-печати. Представленная на рис. 5 диаграмма показывает, что 25\% исполнителей отказываются от разработки и готовы лишь изготовить продукт по предоставленным заказчиком файлам. 13\% исполнителей, напротив, не имеют оборудования или не могут изготовить изделие по каким-то другим причинам, но способны его разработать. Большинство же исполнителей (62\%) готово работать с любыми заказами, то есть может разработать продукт по описанию заказчика и изготовить его. Таким образом, люди, далекие от разработки и производства - а это основная масса заказчиков, нуждающихся

62\% Исполнители, готовые разработать и произвести продукт

25\% Исполнители, готовые лишь произвести продукт

13\% Исполнители, готовые лишь разработать продукт

Рис. 5. Опрос исполнителей: тип работы (3D-принтеры)
87\% Исполнители с оборудованием

13\% Исполнители без оборудования

Рис. 6. Опрос исполнителей: наличие оборудования (3D-принтеры)

в продукции 3D-принтеров, - смогут найти себе подходящего исполнителя.

Аналогичный анализ произведен для определения соотношения исполнителей, работающих с оборудованием и без него. Из диаграммы на рис. 6 видно, что подавляющее большинство исполнителей (87\%) имеет оборудование для изготовления продукта. В то же время есть малая часть исполнителей (13\%), не имеющих оборудования, то есть занимающихся лишь разработкой. Присутствие последних на платформе также имеет смысл для заказчика: в таком случае сервис может быть применен для коллективного использования не только производственных мощностей, но и профессиональных навыков отдельных людей. С точки зрения исполнителя это означает, что ему не обязательно иметь оборудование, чтобы быть востребованным.

Обобщая вышесказанное, можно заключить, что платформа обеспечит исполнителей заказами и даст возможность сдавать оборудование в аренду. Заказы и аренда, загрузив работой простаивающие станки, увеличат интенсивность использования малых активов и, следовательно, обеспечат дополнительный доход их владельцам; возможно, им удастся привлечь постоянных клиентов и таким образом еще больше укрепить свое положение на рынке. Агрегация исполнителей в одном месте и на одинаковых условиях позволит уравнять их шансы на получение заказов, а также исключить или сократить издержки на создание и поддержку собственных сайтов и систем онлайн-заказов.

Заказчик получит в свое распоряжение удобный сервис для заказа и аренды оборудования. Время поиска наилучшего исполнителя, оформления заказов и резервирования оборудования кратно сократится, а заказ у ближайших исполнителей позволит сэкономить на доставке.

\section{ЛИТЕРАТУРА}

1. Шваб к. Четвертая промышленная революция / Пер. с англ. - М.: Эксмо, 2019. 209 c.

2. Goodwin T. The Battle Is For The Customer Interface. TechCrunch, 2015 r. https://techcrunch.com/2015/03/03/ in-the-age-of-disintermediation-the-battle-is-all-for-thecustomer-interface

3. Вебинар "Виртуальная Фабрика» / https://technet-nti.ru/ news/7290 


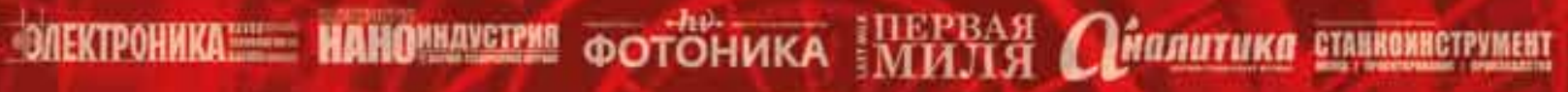

$$
\begin{aligned}
& \text { ИНФОПРО СТРАНСТВО } \\
& \text { ФЕССИОНАИОВ }
\end{aligned}
$$

TEXHOСФЕРA

\section{Мы на $\triangleright$ YouTube}

\section{Подписывайтесь}

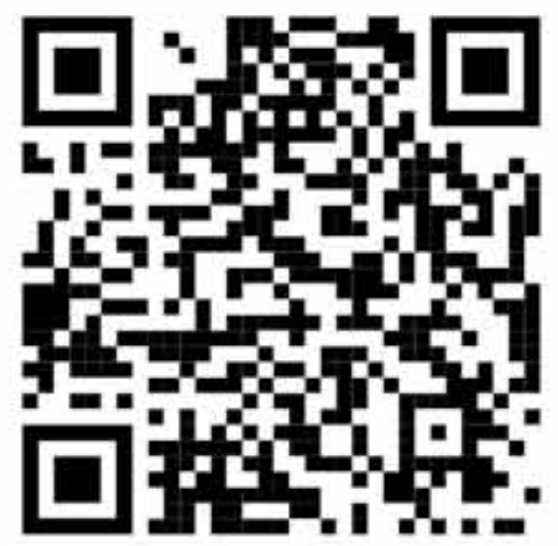

ГЛАВНАЯ

Последние опубликованные видео

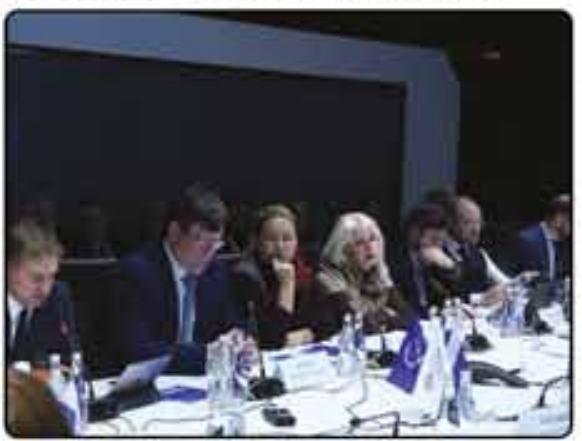

Заседание, посвнщенное обгужденио Стратеги разиітия злектроммои npombitunethoct P PDD

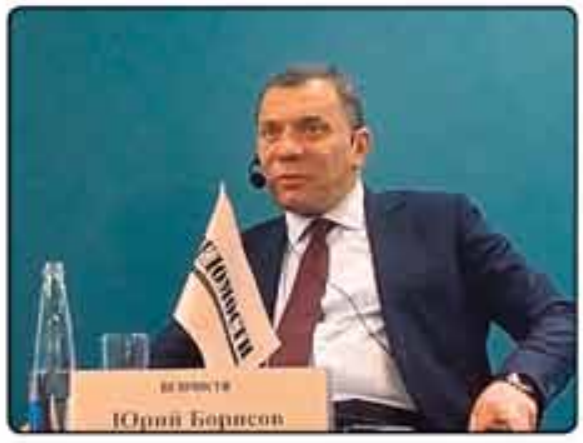

Puhlic Talk c zastecrumeness Председателя Правительства Россиїской Федерания 10.И. Борисопым
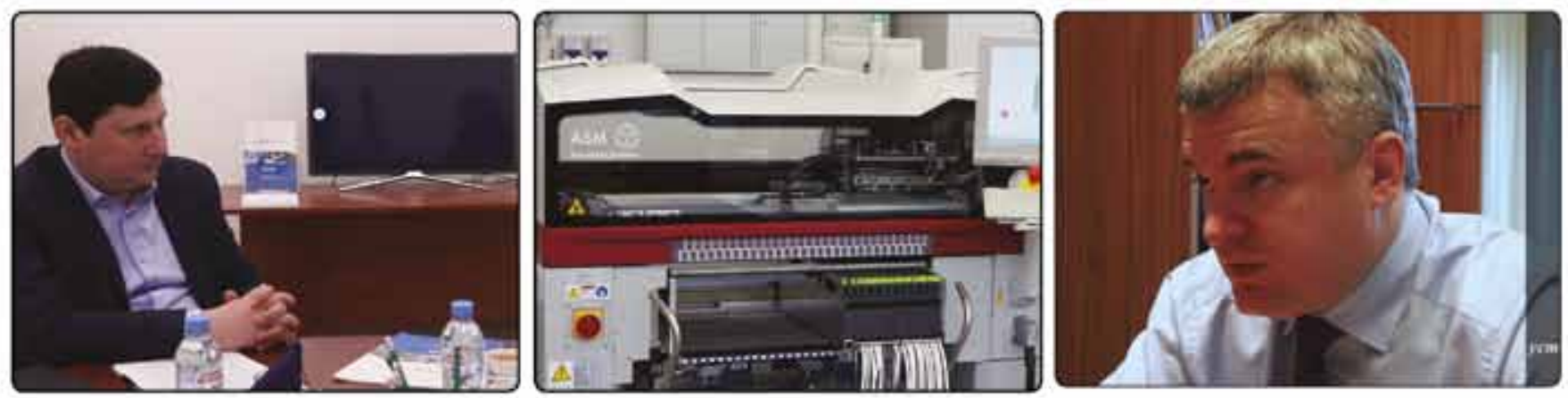